\title{
Município e planejamento: reparações
}

Municipality and planning: reparations

\section{Municipio y planificación: reparaciones}

Municipalité et de la planification: reparations

\author{
Eduardo Yázigi* \\ (http://www.skoob.com.br/autor/7348-eduardo-abdo-yazigi)
}

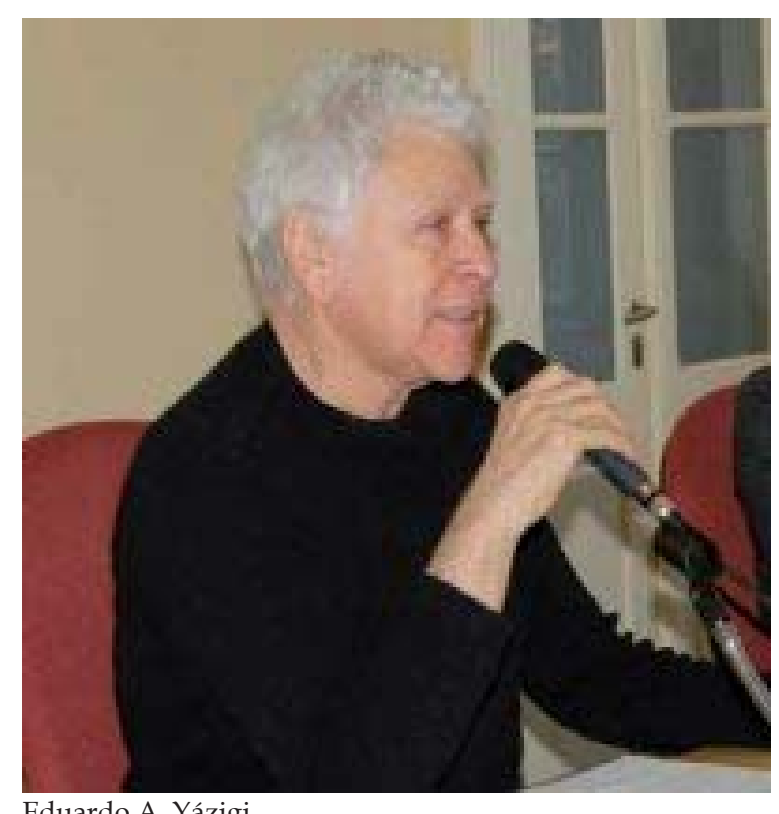

Eduardo A. Yázigi

\section{Introdução}

Foi com especial prazer que recebi o convite da Professora Maria Augusta Castilho para comentar suas indagações. Considero suas colocações muito importantes porque o desejo de modificar e aprimorar nosso espaço de vida só se realiza através de progressivas e constantes intervenções políticas no território. A Geografia, a História e outras disciplinas que lidam com espaço e sociedade dependem de um rigoroso conhecimento e crítica da realidade mutante. Como criticar o Brasil consiste de tarefa banalíssima, é preciso, entretanto, identificar que a mudança se opera mediante políticas públicas e ações cidadãs e que o planejamento urbano e regional é um dos principais instrumentos. Só espero que os breves comentários que seguem possam trazer alguma luz sobre as inquietações que tiram nosso sono e causam cócegas no que devemos fazer e como.

\section{O que é o planejamento urbano?}

Considero o planejamento urbano um dos principais ramos das políticas públicas, por ser o instrumento que melhor permite regular a vida social sob seus aspectos relacionais com o meio. Ele é parte de uma grande gama de especialidades destinadas a administrar a cidade em caráter permanente, servindo-se de normas, construções e fluxos convencionados pela ordem democrática.

Uma reparação a ser feita logo de início concerne à inseparabilidade entre o planejamento urbano e o regional. De fato, nos tempos da cidade isolada, forçada a se regular conforme fosse sua autonomia, ainda era possível circunscrever algumas iniciativas nos limites do município. Não obstante, as múltiplas relações de interdependência que caracterizam o fenômeno da metropolização, cada vez maior, anulam tentativas de se pretender resolver os problemas de modo paroquial. Não por acaso, desde a década de 1970, criaram-se regiões metropolitanas nacionais, acompanhadas de uma legislação que as força a realizar um planejamento conjunto dos fatores que só podem ser resolvidos em comum: zoneamento industrial, serviços de tubulações que devem atender uma rede de lugares, como por exemplo, a água, cujos reservatórios também são de interesse metropolitano; a rede de transportes... tudo o que garante a integração dos municípios que fazem parte da região considerada. Ora, se um grande número de cidadãos trabalha na região central de São Paulo, mas reside nos municípios periféricos, torna-se óbvio e obrigatório que a

\footnotetext{
* Universidade de São Paulo, São Paulo, SP, Brasil.
} 
política habitacional deva ser resolvida com o envolvimento de municípios vizinhos: aí se inaugura para sempre o princípio de planejamento urbano e regional. Mais ainda: lá onde o desenvolvimento acontece fora das regiões metropolitanas, fica facultado ao poder central ou estadual criar novas regiões de planejamento ou, decididamente, metropolitanas. Esta é a sina do planeta, queiramos ou não.

Contamos com mais de 5.500 cidades no território nacional e dispomos de um índice que, há mais de trinta anos, mede as melhores cidades brasileiras para se viver. Desde seu início, ele cotizava vários itens funcionais qualificadores das cidades, tais como número de leitos hospitalares por habitante; conexões domiciliares com água e esgotos; vagas no sistema educacional, hospitalar etc. Pode-se praticar um refinamento que permite examinar, setor por setor, resultando que, por exemplo, em cada um deles, a medida seja dada por um alto grau de medidas. Os números são efetivamente importantes porque nos revelam a densidade de vários aspectos da realidade, mas devemos ter extrema cautela ao considerá-los. Cito um simples fato que nos alerta sobre a deformação da realidade. A Universidade de São Paulo, por exemplo, regozija-se com números, ao divulgar, amplamente, quantos milhares de doutores e mestres formou a cada ano. Não obstante, o aprofundamento real nesse universo causa extrema decepção quando se tem conhecimento de significativas partes do todo: doutorados que jamais poderiam ser agraciados com tão nobre título, cujo rigor científico é ignorado; mestrados rebaixados a trabalhos de conclusão de curso... Portanto é preciso muita cautela com o uso dos números.

Um retrato mais próximo da realidade exigiria um complexo e minucioso sistema de avaliação. Em meu último livro ("Reencantamento da cidade. Miudezas Geográficas e devaneio") coloquei um desafio ao Brasil. Quando afirmamos que o Rio de Janeiro é uma cidade maravilhosa, tendo merecido inclusive o título de patrimônio da humanidade, de onde até onde vai sua mancha urbana "maravilhosa" que vara as linhas do horizonte? Quem é capaz de cartografá-la e com quais critérios? O que de fato sobra se do Rio desconsiderarmos o que não foi produto do homem, isto é, os dons inerentes à natureza da criação? Suas maravilhas urbanas terminam nas periferias, ou incluímos o "Complexo do Alemão" nesta cartografia que ignora o medo como fator de desmaravilhamento?

Nossas avaliações correm outros perigos deformadores. É preciso não confundir a sensação alegre de viver num lugar, com o que ele de fato é. Quando se diz que muitas cidades suecas apresentam virtudes urbanísticas e urbanas preciosas, comumente ouvimos a seguinte contrarresposta: "Eh!, mas essa gente vive se matando!" - como se não aguentassem suas condições rígidas de vida... Admitamos que isso seja lá verdade. Mas que resposta daremos ao comparar o número de suicidas suecos com o número de mortos no trânsito por causa de nosso desvario impune com os autos? E as vítimas de crimes escabrosos, jamais punidos, por balas perdidas, por acerto de conta de gângsters, por prédios que desabam, por arrastões durante a "alegre sensação de viver num lugar", pela incapacidade de projetar arquitetura...?

Já existe uma doença do divã do psicanalista cuja origem está na cidade, como demonstrado por James Hillman em seu livro "Cidade e Alma". A FAPESP divulgou pesquisa realizada em 2012 revelando um dado estonteante: $30 \%$ da população urbana de São Paulo sofrem de Transtorno Impulsivo Intermitente. Traduzido em miúdos: um povo com ataques de violência que se repetem ao longo do tempo, evidenciando que somos um povo sem educação. Aliás, na opinião da professora Emérita da USP, Marilena Chauí, encontrável no Youtube, nossa classe média é a mais sem educação do mundo. Já eu entendo que esse fato atinge todos os segmentos sociais. Isto me reporta a outro dado fulgurante: nosso sistema normativo é hipócrita; aqui ignoramos olimpicamente aquilo que é um dos maiores fundamentos da democracia: a isonomia, a lei ser igual para todos. Milton Santos, Agnes Heller ou Berger são apenas alguns, entre centenas de autores, que lembram: todo território tem de possuir normas! E as nossas, por onde andam? Que justiça é essa que prende um cidadão que roubou para comer e deixa à solta os eleitos de colarinho branco que prejudicam milhões de pessoas?

Após essas breves ilustrações de como a realidade profunda ou a civilidade são decisivas à qualidade de vida urbana, farei outros 
comentários que nos remetem à indagação em pauta. Planejamento urbano sem bases pedagógicas, normas efetivas e vigiadas não resolve nossa vida nas cidades.

O planejamento urbano depende antes de tudo de discursos fundadores, porque $\mathbf{o}$ discurso sempre precede à cidade. Sempre! E agora, de que discursos (ou teorias) diferenciados dispomos para milhares de cidades? Onde estão as políticas urbanas e culturais para quase seis mil delas? Com quais critérios foram eleitos seus executivos e legisladores? Lutadores de judô? De boxe? Palhaços do pocotó? Jogadores de futebol? Atores e atrizes de carinha bonita? Locutores famosos? Os perfis dos eleitos, várias vezes revelados por institutos de administração pública, evidenciam-lhes a franca incapacidade de equacionar problemas técnicos e éticos. Dentre estes, denuncio alguns que contribuem decididamente para a deterioração do meio urbano, verdadeiras metástases que estupram a cidade.

O planejamento urbano é extremamente trabalhoso e deveria também se preocupar com microplanejamentos. As vergonhosas calçadas brasileiras, verdadeira Casa da Mãe Joana, são a prova mais cabal de nossa incapacidade, de nosso baixo grau de exigência da cidadania. Ser dotado de consciência planejadora deixou de ser ato individual, pois o processo do planejamento depende de uma multitude de saberes; depende de escalas que vão da filosofia de vida até chegar ao nível de 1:1, senão passamos a vida em carroças que chamam de ônibus, ou em lajes de concreto consideradas parques... Quase dois séculos após o urbanismo ser inventado como disciplina dotada de rigor, continuamos com expedientes acaboclados do "dá-se um jeitinho"...

\section{As cidades brasileiras têm realizado o plane- jamento urbano de forma satisfatória?}

A resposta a esta pergunta deriva da anterior. A resposta é não! Não, porque o planejamento possui dois polos que não sabemos ver enquanto duplo aspecto: só somos capazes de agir no tópico, no buraco em frente da casa de cada um. Faz parte da cultura política brasileira não lutar pelo outro lado da questão: das instituições. Como dizia Gramsci, o desenvolvimento não se consegue com arrebatamentos sonhadores, mas com uma lenta construção de instituições. Para piorar, sequer dispomos de uma "memória do planejamento", que com suas chamadas servisse de referência para todas as construções a serem feitas. Pior ainda: quando se escrevem, nos documentos oficiais, as etapas do planejamento, define-se o curto, médio e longo prazo. O longo prazo é raramente acionado, porque ele não começa daqui a dez ou vinte anos, e sim no momento preciso da tomada de consciência, no hoje de sua aprovação. Então, neste Brasil, a maioria dos fatores estruturais são empurrados para as Calendas Gregas.

Enfim, a cidade brasileira vive eternamente no varejo. O perigo são as varejeiras que surgem na vida cotidiana dos cidadãos.

\section{Como a alma do lugar pode despertar o senti- mento de pertença para que os habitantes da comunidade possam ter melhor qualidade de vida?}

Eu diria que, quando existe uma relação amorosa entre o cidadão e a cidade, é a alma do lugar que se desperta - poderia ocorrer e se limitar a um simples bairro. Mas claro que, para isso, é preciso que os gerenciadores de cada setor da cidade cumpram o que se espera da cidadania plena. Pode também acontecer o inverso, isto é, o divórcio de uma coisa que começou bem, mas se deixou degringolar.

O principal problema da potencialização da cidadania brasileira é que os cidadãos e as autoridades não lutam para que a cidade seja a casa de todos. O cidadão comum costuma cuidar de sua casa com brilho, mas jamais considera que sua responsabilidade deve ir além de seu muro com a rua.

Nos anos 1960, as esquerdas divulgavam uma velha ideia dos movimentos socialistas do começo do século XX: "A religião é o ópio do povo", supondo equivocadamente que ela fosse alienante - sobretudo hoje em que grandes alas cristãs andam seriamente empenhadas na justiça social, a exemplo do atual Papa Francisco. E então, quem foi que ficou com o tal ópio? Doa a quem doer: o futebol! Se consagrássemos à questão urbana $1 / 3$ de nossa paixão por esse esporte, as cidades seriam muito melhores para todos. Os movimentos sociais nas ruas do Brasil a partir de Junho de 2013 dão os primeiros sinais 
de recusa dos exageros futebolísticos. Nas manifestações rueiras de São Paulo, chegouse a exibir um cartaz dizendo: "Cala a boca, Pelé". Só o tempo dirá se foi uma consciência real ou não.

Alma do lugar, portanto, não se encomenda em sessões espíritas.

Cite alguma cidade brasileira que desenvolveu ou não, a contento, o planejamento urbano.

Sou extremamente sensível às cidades porque sou um pedestre de carteirinha. De mim o tal de flaneur do Baudelaire não ganha! Aliás, não acredito em nenhuma teoria da cidade cujo autor não tenha virado ruas e avenidas de ponta a ponta, em dias de chuva, frio, calor, de segunda a segunda, de dia e de noite, todos os dias do ano, porque a cada hora a rua vira outra coisa e revela um clima vivencial diferente. Assim, quando visito uma cidade nova, recuso-me percorrer mais do que um museu. Meu instinto é vadiar pelas ruas e calçadas, entidades que são o retrato da índole de seus habitantes e de sua administração. Brasília foi concebida como majestade tropical, mas agora tentem ver como as coisas são de perto, tentem ver a distância abissal entre seus Palácios e a Avenida W3. No Brasil, toda cidade se denuncia proporcionalmente à distância de suas áreas nobres. Estranho, não? Lado Nobre e o Resto!

Sim, as cidades mudam no tempo. Morei anos e anos em Paris, conhecia quase todas as ruas. Mas hoje em dia não posso dizer a mesma coisa. O Ser se modifica com o Tempo. O que era não é mais. A gestão da cidade deve ser uma eterna vigilância. Nossa casa também não é? E o quê não é?
Dentre as cidades, duas me chamaram atenção, ambas do Sul: Santa Cruz do Sul, RS, e Curitiba, PR. Não falta quem critique Curitiba. Já ouvi afirmações deste tipo: “É, mas a Ópera do Arame faz eco!" ou então: “É, mas Curitiba tem favela, tem violência"... Bem... o eco da Ópera de Arame é lá com o arquiteto. Infelizmente a maioria dos cidadãos não realiza que existe uma premissa que impede as coisas de se realizarem mais a contento: os limites da autonomia municipal. A favela e a violência não se controlam totalmente no âmbito municipal, porque muito do que acontece no país irradia por todo o território: renda, corrupção, crises, educação etc. Todo lugar bem sucedido está fadado à favelização, salvo alguns lugares como Águas de São Pedro, SP, que não tem favelas porque é o menor município do Brasile não sobra lugar: os pobres vão para os municípios vizinhos. Ou então, a bela Penedo, divisa de São Paulo com Rio, cujas ruas de fada para turista ver são possíveis só porque se jogam os "párias" para o outro lado da Via Dutra. É a política de avestruz regendo o Brasil.

Outra questão gravíssima que turva o ato de planejar são as filiações partidárias e micropartidárias. O brasileiro decidiu que não deve apoiar o que o inimigo faz porque ele é inimigo e não pela virtuosidade da coisa. Então você ficou com inveja do que o prefeito foi capaz de fazer? Ora, espezinhe o cara mostrando que sabe fazer melhor!

Conheci também um pequeno município paulista - São Simão - que andou como um brinco porque teve dois prefeitos, com dois mandatos cada um, que disputavam perfeição. Ambos faleceram, não sei a quantas anda tantos anos depois. OSer e o Tempo nos assombram, porque a única permanência do Universo é a impermanência. 